\title{
APROXIMACIÓN A LOS PROBLEMAS DE APRENDIZAJE DE LA ESTRUCTURA Y FORMACIÓN DEL SUELO EN EL ALUMNADO DE 12 A 17 AÑOS
}

\author{
YUS RAMOS, R. Y REBOLLO BUENO, M. \\ Centro de profesores de la Axarquía. Vélez-Málaga (Málaga).
}

\section{SUMMARY}

In a longitudinal study, carried out with 12.17 year old students, to know learning obstacles and their evolution through schooling years, on the scientific concept of soil, we have found important data of learning problems on these topics, showing the established inefficiency of transmission of scientific knowledge to conceptual change. Lastly, we point out some implications for the teaching and significative learning of these concepts.

\section{INTRODUCCIÓN}

Dentro de la relativa escasez de aportaciones en torno a Ias dificuitades del aprendizaje de los conceptos geológicos, destacan los relativos al suelo y la edafogénesis. De hecho, el único antecedente que hemos podido hallar se encuentra en el trabajo de Happs (1982), gran parte de cuyas conclusiones, especialmente centradas en aspectos estructurales, se confirman en el estudio que aquí se expone. Contrasta esta laguna con la abundante profusión de estudios en otras temáticas de las ciencias de la naturaleza, aun a pesar de que esta temática aparece reiteradamente en diversos currículos de los distintos niveles educativos.

El presente estudio forma parte de una modesta investigación realizada durante el seguimiento a la aplicación de una propuesta curricular de Ciencias de la Naturaleza en la etapa 12-16. Su objetivo era aproximarnos a la comprensión de los problemas de aprendizaje que observábamos sobre el concepto científico de suelo, en el alumnado de este segmento educativo.

Para realizar dicho estudio, tras un sondeo preliminar selectivo en determinados grupos de alumnos de la mencionada etapa, se elaboró un test para el diagnóstico de las representaciones de los alumnos sobre diversos aspectos del concepto científico de suelo, englobando tanto los problemas debidos a preconceptos oconcepciones infantiles, como los problemas derivados de la polisemia del término «suelo». Dicho instrumento (Anexo l) con- sistió en trece ítems de dos apartados: A (contestación đe elección múltiple) y $\mathrm{B}$ (explicación de la respuesta escogida). Dicho test fue presentado a 294 alumnos de cinco centros educativos ( 3 de EGB y 2 de BUP), comprendiendo alumnos de 12-17 años (desde $7^{9}$ de EGB a $3^{\circ}$ de BUP). Todos los alumnos encuestados habían tenido algún contacto académico con el concepto científico de suelo, sea en años anteriores o en el año en curso.

\section{RESULTADOS}

\section{A) ASPECTOSESTRUCTURALES DEL CONCEPTO DE SUELO}

Un grupo de cuestiones iban dirigidas al estudio de las representaciones de los alumnos sobre los aspectos estructurales del suelo, esencialmente descriptivos oestáticos, que suelen ser los que mayor énfasis adquieren en los currículos de ciencias de la naturaleza. A continuación describimos los resultados de este sondeo en todos los riveles educativos:

\section{Concepto de suelo}

Este primer grupo fue abordado con el ítem $n^{0} l$ (Anexo l). Las respuestas aceptables obtenidas en cada 
apartado pueden advertirse en la siguiente tabla (Gráf. 1):

\begin{tabular}{|c|c|c|c|c|c|c|c|c|c|c|c|c|}
\hline \multirow[t]{2}{*}{ I } & \multicolumn{2}{|c|}{$\begin{array}{c}7^{2} \mathrm{EGB} \\
12.13 \\
\end{array}$} & \multicolumn{2}{|c|}{$\begin{array}{c}8^{\circ} \text { EGB } \\
13-14 \\
\end{array}$} & \multicolumn{2}{|c|}{$\begin{array}{c}\mathbf{1}^{\mathbf{B}} \text { BUP } \\
14-15 \\
\end{array}$} & \multicolumn{2}{|c|}{$\begin{array}{c}2^{2} \text { BUP } \\
\text { 15-16 } \\
\end{array}$} & \multicolumn{2}{|c|}{$\begin{array}{c}\text { 30 BUP } \\
16.17\end{array}$} & \multicolumn{2}{|c|}{ General } \\
\hline & A & B & A & B & A & B & $\mathbf{A}$ & B & $\mathbf{A}$ & B & A & B \\
\hline 1 & 43,8 & 6,8 & 59,2 & 1,3 & 82,4 & 19,6 & 70,0 & $\mid 10,0$ & $50,0 \mid$ & 4,5 & 59,8 & 7,8 \\
\hline
\end{tabular}

En el estudio preliminar se advirtió que los alumnos tendían a usar el término «suelo» exclusivamente para designar la superficie que se pisa y para referirse al suelo natural preferían utilizar el término de «tierra». Se mostraba así un posible obstáculo en los procesos de enseñanza/ aprendizaje, derivados de la polisemina del término "suelo», en que la acepción vulgar no coincide con la científica. Así se detectó en el test, donde sólo el 59,8\% del total entrevistado elegían la respuesta científicamente aceptable al apartado A. Pero sólo el 7,8\% de los mismos fueron capaces de dar una explicación aceptable. No obstante, hemos de reconocer que la respuesta aceptable del apartado A (b) puede ser confundida con la no aceptable $(a)$, lo que quiere decir que gran parte de los alumnos que eligieron la opción $b$, en reałidad tenfan un concepto đe suelo más cercano a la concepción que expresa $a$, es decir: «la superficie que pisamos». Esto se pudo deducir a partir de las restantes contestaciones a otras preguntas del test, donde se advertía la coherencia con esta concepción de suelo. En cuanto a la evolución del concepto de suelo a lo largo de la etapa considerada, se puede advertir (Gráf. 1) que las contestaciones aceptables alcanzan su máximo valor entre el alumnado de 14-15, que representa el $1^{2}$ de BUP sometido a la experimentación de la Reforma posiblemente por un tratamiento más reciente e insistente sobre esta temática. Llama la atención la escasa diferencia de concepción entre alumnos de $12-13$ y de $16-17$, lo que demuestra que muchos alumnos circulan por nuestra aulas sin apenas modificar su concepto de suelo, o bien no se asocia el término a su acepción científica a pesar de ser una temática usual en los currículos escolares.

Aunque algo más de la mitad de los alumnos eligieron la respuesta correcta, lo cierto es que sus explicaciones (apartado B) eran bastante pobres cuando no inaceptables científicamente. En cursos más avanzados se advierte el resultado de la instrucción previa, aunque con un componente predominantemente geológico, decreciendo de ruevo la riqueza de las explicaciones en los cursos más adelantados. Prácticamente en ningún caso se describe el suelo como un producto de la interacción entre organismos vivos e inertes, si bien en algún caso aislado se apunta una interdependencia, aunque lineal.

Pero la gran mayoría de las explicaciones eran inaceptables, demostraban una concepción inercial de suelo, como una superficie que pisamos. Si bien la frecuencia de este tipo de representaciones era mucho mayor en los primeros años, su evolución no es destacable. A partir de $8^{0}$ de EGB se advierte la utilización del concepto de «estructura de la Tierra», de tal suerte que el suelo viene a significar la capa más superficial, usando un criterio inadecuado. Otras explicaciones que resaltan denotan una identificación del suelo con terreno de cultivo, siendo esto tan sólo evidente en los primeros cursos.

Como mostraremos más adelante, está concepción de suelo, en su acepción vulgar como superficie que normalmente pisamos, es coherente en las contestaciones a otras dimensiones de dicho concepto, que aparecen en eI test. De este modo, un alumno que tenga este concepto pensará que el factor más importante en la formación del suelo es el tipo de roca («porque cuanto más dura sea mejor resistirá el pisoteo») o que el suelo no está formado por seres vivos; que el lugar más idóneo para formarse un suelo es el campo de cultivo (porque «allí no hay obstáculos para andar, como sucede en el bosque») o bien en un bosque (siempre que «se talen los árboles y se construya una carretera»); y que el suelo se forma mejor en clima árido (pues «al no llover no se embarra el suelo y se hace más duro").

\section{Componentes del suelo}

Este aspecto fue abordado desde el ítem $n^{2} 6$ (Anexo I). Las respuestas aceptables obtenidas en cada apartado pueden advertirse en la siguiente tabla (Gráf. 2):

\begin{tabular}{|c|c|c|c|c|c|c|c|c|c|c|c|c|}
\hline & & \multicolumn{2}{|c|}{$\begin{array}{c}\text { 80 EGB } \\
13-14 \\
\end{array}$} & \multicolumn{2}{|c|}{$\begin{array}{c}1^{9} \text { BUP } \\
\text { 14-15 } \\
\end{array}$} & \multicolumn{2}{|c|}{$\begin{array}{c}2^{9} \text { BUP } \\
\text { 15-16 } \\
\end{array}$} & \multicolumn{2}{|c|}{$\begin{array}{c}3^{2} \text { BUP } \\
16-17 \\
\end{array}$} & \multicolumn{2}{|c|}{ General } \\
\hline & A & & & & & & & & & & & \\
\hline & & & & & & & & & & & & \\
\hline
\end{tabular}

En esta pregunta se plantea una serie de opciones sobre la composición grosera del suelo. Se pretende confirmar una visión de suelo, advertida en el estudio preliminar, esencialmente abiótico y carente de aire. El resultado global muestra que algo más de los alumnos de la etapa 12-17 no tienen una noción aceptable de la composición de' suelo. El hecho de que el $40,4 \%$ de los alumnos seleccionaran la respuesta aceptable en el apartado A (opción $d$ ) no siempre iba, una vez más, aparejada a una fundamentación, ya que el nivel de explicaciones aceptables era mucho más bajo $(9,1 \%)$.

En cuanto a la evolución a lo largo de la etapa considerada (Gráf. 2), se advierte de nuevo un proceso de progresión hasta alcanzar un cenit en $1^{\circ}$ de BUP $(60,8 \%)$, para decrecer paulatinamente en los últimos cursos. Llama la atención la escasa diferencia de niveles alcanzados entre los primeros cursos (en torno al $30 \%$ ) y los últimos (en torno al $40 \%$ ), aun a pesar de que estos últimos han debido recibir mayor información sobre este tópico. El hecho que destaque $1^{\circ}$ de BUP puede explicarse por ser alumnos sometidos a un reciente proceso de instrucción al respecto. No obstante, es destacable el bajo nivel de explicaciones (apartado B) que, curiosamente, aumenta en proporción en $3^{\circ}$ de BUP.

Entre las explicaciones aceptables a la opción correcta del apartado A, figuran unas que hacen referencia al 
papel del aire y el agua en la vida del suelo, otras a la localización de este elemento singular. A veces explican el origen y función de estos componentes, aunque sin nombrar el papel del atre, denotando una visión del papel de los seres vivos restringido exclusivamente a la acción de los restos o cadáveres. En raras ocasiones se atribuía otro papel a los seres vivos y otras veces son más pobres en explicaciones. Aunque otras explicaciones aceptables hacian referencia a opciones del apartado $\mathrm{A}$ que no eran las más correctas, las hemos contabilizado como tales. Entre éstas figuran las que se refieren a la opción $e$, mostrando una cierta visión ecológica del suelo, aunque de nuevo otorgando a los seres vivos un papel restringido a la descomposición de sus cuerpos.

Entre las explicaciones no aceptables a las opciones no válidas del apartado $\mathrm{A}$, destaca un primer grupo que atribuye al suelo un componente exclusivamente inorgánico, denotando el uso de una concepción de suelo como «superficie para andar o pisar», ya detectada en otros íterns. En otros casos se muestra un claro rechazo a la idea de que los seres vivos formen parte del suelo. Un grupo de respuestas explican el origen y función de los componentes, en algún caso con una dimensión ecológica. En los últimos cursos se apuntan otros componentes no previstos en el ítem.

\section{Estructura del suelo}

Este capítulo fue probado a través de los items $n^{Q} 10$ y $n^{\circ}$ /3 (Anexo I). Las respuestas aceptables obtenidas en cada apartado pueden advertirse en la siguiente tabla (Gráf. 3 y 4 ):

\begin{tabular}{|c|c|c|c|c|c|c|c|c|c|c|c|c|}
\hline \multirow[t]{2}{*}{ It } & \multicolumn{2}{|c|}{$\begin{array}{c}7^{2} \text { EGB } \\
12 \cdot 13\end{array}$} & \multicolumn{2}{|c|}{$\begin{array}{c}8^{2} \text { EGB } \\
13 \cdot 14\end{array}$} & \multicolumn{2}{|c|}{$\begin{array}{l}1^{9} \text { BUP } \\
14 \cdot 15\end{array}$} & \multicolumn{2}{|c|}{$\begin{array}{c}20 \mathrm{BUP} \\
15 \cdot 16\end{array}$} & \multicolumn{2}{|c|}{$\begin{array}{c}3^{9} \text { BUP } \\
16.17\end{array}$} & \multicolumn{2}{|c|}{ General } \\
\hline & A & B & $\mathbf{A}$ & & $A$ & B & $A$ & H & $\mathbf{A}$ & & A & B \\
\hline & 1,3 & & & & 0,0 & 0,0 & & 0,0 & 0,0 & & & \\
\hline & 6,3 & 8,2 & & 3,9 & 92,2 & 41,1 & 92,0 & 42,0 & 95,4 & 88,6 & 86,0 & 30, \\
\hline
\end{tabular}

Con el ítem $n^{2} 10$ se pretendía probar el concepto de «horizonte» que tenían los alumnos, ya que como detectamos en el estudio preliminar, se tendía a confundir «horizonte» con «estrato», dentro de un marco conceptual de edafogénesis cercana a la sedimentación. Para probar la aplicación del principio de superposición estratigráfica, se acudió al item $n^{2} 13$, donde efectivamente se confirmó el conocimiento general de este principio.

Si examinamos los resultados globales de la etapa considerada, advertiremos la estrecha correlación entre los resultados de ambos ítems. En efecto: mientras que Ia inmensa mayoría de los alumnos encuestados mostraban una concepción errónea de horizonte, probado en el j́tem $\mathrm{n}^{\circ} 10$ (sólo el $1,7 \%$ dio una respuesta aceptable), otra gran mayoría mostraba su conocimiento y aplicación del principio de superposición estratigráfica, probado en el ítem no 13 (el 86,0\% de respuestas aceptables). Esto significaba una confirmación de nuestras observacio- nes: el alumno consideraba el horizonte como un estrato. Pese a todo, el nivel de explicación de la opción elegida en el f́tem $n^{*} 13$ (apartado B) era mucho más pobre, alcanzándose sólo el $30,6 \%$, a pesar de que muchas explicaciones eran prácticamente tautologías.

En cuanto a la evolución de esta concepción a lo largo de la etapa considerada (Gráf. 3 y 4), se advierte una tónica general muy pobre en el ítem $n^{0} 10$, con una emergencia poco significativa en $8^{\circ}$ de EGB $(3,9 \%$ con un nivel de explicación cercano: $2,6 \%$ ). Llama la atención el hecho de que $3^{\circ}$ de BUP carezca de respuesta aceptable alguna en el apartado A y que ni $2^{\circ}$ ni $3^{\circ}$ de BUP tengan explicaciones aceptables en el apartado B. En el item $\mathbf{n}^{*}$ 13, como hemos indicado, la situación se invierte, mostrándose una tónica general por encima del $80 \%$ de respuestas aceptables en el apartado $\mathrm{A}$, bajando algo en $8^{\circ}$ de EGB. Las máximas puntuaciones se obtuvieron en $3^{9}$ de BUP y aquí es donde también se obtuvo la máxima puntuación de respuestas aceptables en el apartado B, si bien éstas solían ser muy pobres y casi tautológicas.

Si nos centramos en el ítem $n^{0} 10$, entre las muy escasas explicaciones aceptables al apartado A (opción b) figuran argumentos pobres que eran prácticamente los únicos que argỉían la elección en toda la etapa. En cambio, la opción más general elegida en el apartado A fue la $a$, que señalaba el horizonte A como el más moderno, lo que denotaba la aplicación del principio de superposición estratigráfica, o bien se refiere al proceso de erosión y sedimentación, o incluso a la presencia de plantas. En ocasiones se le atribuyen cualidades que no parecen tener relación con la antigüedad.

Respecto al item $^{\circ} n^{\circ} 13$, las explicaciones fueron muy pobres, cercanas a la tautología. Los alumnos intuían el principio de superposición, pero no encontraban argumentos lógicos para explicarlo. Por ello, eran frecuentes los razonamientos destinados simplemente a confirmar el principio de superposición estratigráfica. Otras veces se acudía a razonamientos algo más elaborados, siguiendo un criterio de pura lógica.

Las restantes explicaciones iban en un sentido no muy diferente, aunque algo más tautológicas. Otras veces la explicación incluía razones sorprendentes, muchas de ellas relacionadas con la mayor o menor exposición a los agentes erosivos, llegando incluso a mostrar confusión con el concepto de suelo. En muy escasas ocasiones se eligieron opciones diferentes, como considerar más antigua la primera capa, lo cual razonaban de forma ciertamente ingeniosa, o bien elegían una opción alternativa. Aunque extremadamente raro, también apareció una opción de capas intermedias.

\section{Profundidad de suelo}

Este aspecto fue probado con el item $n^{2} 4$, inspiradio en el utilizado en el test de Happs (1982), aunque introduciendo algunas modificaciones importantes para nuestros propósitos (Anexo 1). Las respuestas aceptables 
Gráftco 1

TEST DEL SUELO

İtern núm. 1

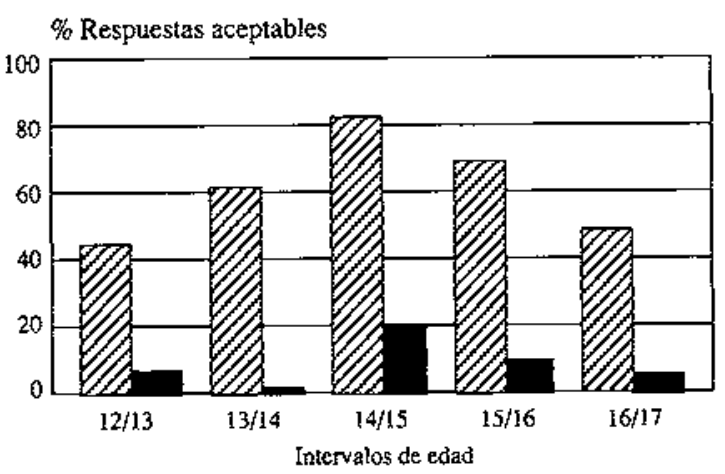

ZX Apartado A

Apartado B

Gráfico 3

TEST DEL SUELO

Îtem nún. 10

$\%$ Respuestas aceptables

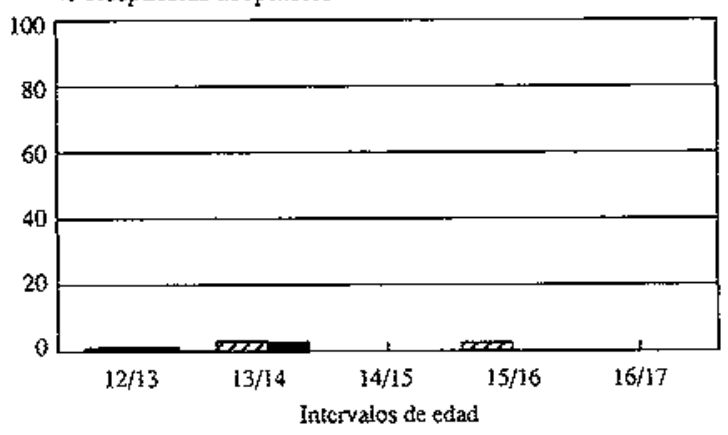

Z7Z Apartado A Apartado B

Gráfico 5

TEST DEL SUELO

f́tem núm. 4

\% Respuestas aceptables

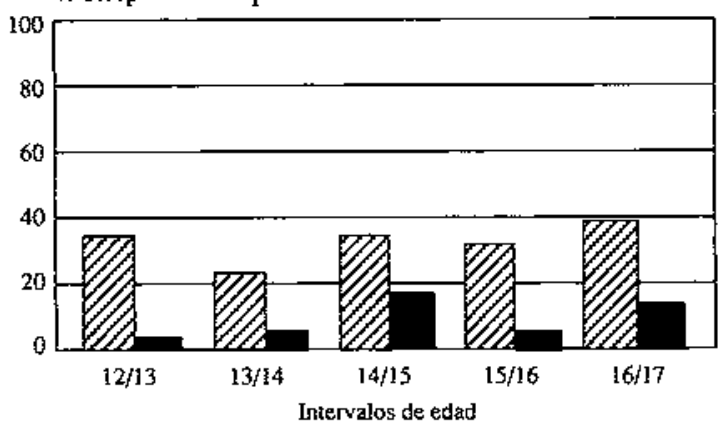

Z7A Apartado A

Apartado B
Gráfico 2

TEST DEL SUELO

İtem núm. 6

\% Respuestas aceptables

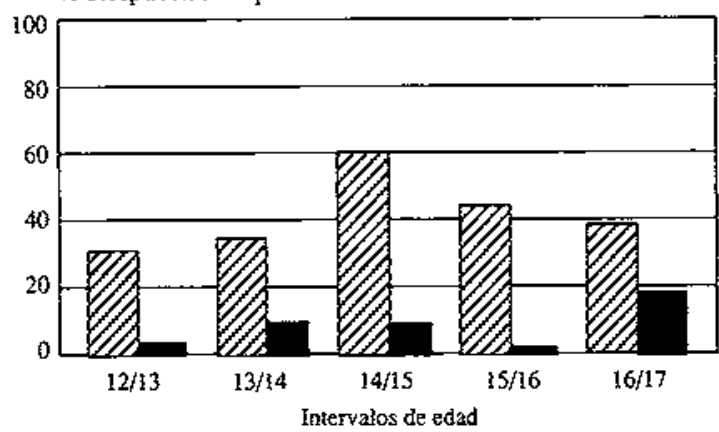

IZA Apartado A

Apartado B

Gráfico 4

TEST DEL SUELO

Ítern nứn. 13

\% Respuestas aceptables

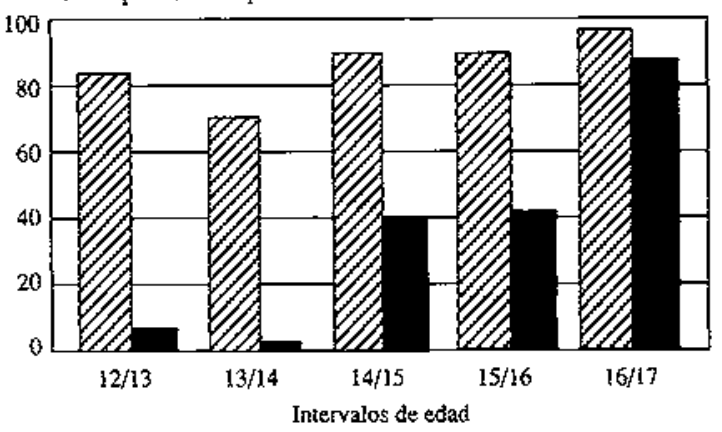

Z7] Apartado A Apartado B

Gráfico 6

TEST DEL SUELO

İtern núm. 9

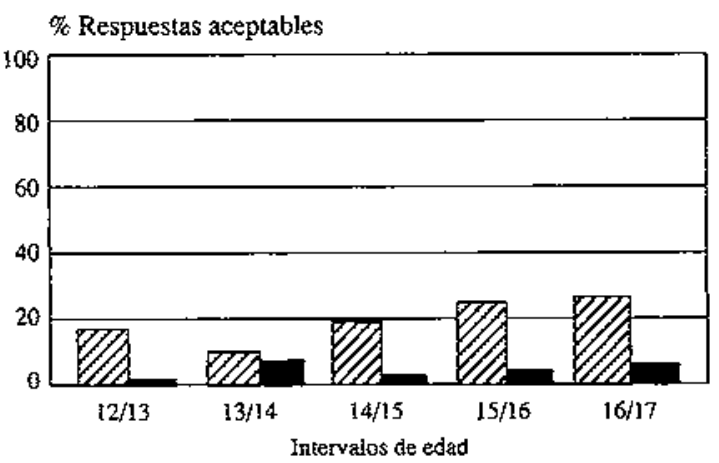

ZZA Apartado A

Apartado B 
obtenidas en cada apartado pueden advertirse en la siguiente tabla (Gráf. 5):

\begin{tabular}{|c|c|c|c|c|c|c|c|c|c|c|c|c|}
\hline \multirow[t]{2}{*}{ It } & \multicolumn{2}{|c|}{$\begin{array}{c}7^{9} \text { EGB } \\
12-13 \\
\end{array}$} & \multicolumn{2}{|c|}{$\begin{array}{c}8^{2} \text { EGB } \\
13.14 \\
\end{array}$} & \multicolumn{2}{|c|}{$\begin{array}{c}1{ }^{0} \text { BUP } \\
14.15 \\
\end{array}$} & \multicolumn{2}{|c|}{$\begin{array}{c}2^{9} \text { BUP } \\
15-16 \\
\end{array}$} & \multicolumn{2}{|c|}{$\begin{array}{c}\text { 30 BUP } \\
16-17\end{array}$} & \multicolumn{2}{|c|}{ General } \\
\hline & $\mathbf{A}$ & B & A & B & $A$ & B & A & B & A & B & $\mathbf{A}$ & $\mathbf{B}$ \\
\hline 4 & 34,2 & 2,7 & 23,6 & 5,2 & 33,3 & 17,6 & 32,0 & 6,0 & 38,6 & 13,6 & 35,3 & 8.1 \\
\hline
\end{tabular}

En el ítem utilizamos intervalos científicamente aceptablès, como el $a$ y el $b$, no incluyendo suelos de más de 10 m (como los lateríticos, de zonas tropicales) por considerarlos fuera del universo conceptual del alumno. Por otra parte, consideramos más aceptable la opción b ya que la a pretendía detectar la acepción vulgar de suelo como superficie que se pisa, como se demostró.

Se trata éste de un aspecto normalmente descuidado en la enseñanza del tema del suelo, posiblemente por considerarse obvio o banal. Sin embargo, como se muestra a partir de los resultados de este test, los alumnos tienen una concepción de la magnitud del suelo muy desproporcionada con la realidad, demostrando una faceta más del concepto vago y confuso que se suele adquirir del concepto «suelo» tras el proceso de enseñanza de este aspecto del suelo.

En efecto, los resultados obtenidos, a escala global en toda la etapa, nos muestran una proporción muy pequeña de respuestas aceptables $(34,0 \%)$, siendo aún mucho menor el nivel medio de explicaciones alcanzado para estas opciones $(8,1 \%)$. La evolución de esta concepción a lo largo de la etapa (Gráf. 5), nos muestra una distribución muy similar, salvo el caso de $8^{\mathrm{D}}$ de EGB, en torno al $30 \%$, si bien el nivel de explicaciones (apartado B) es algo mayor en $1^{\circ}$ y $3^{\circ}$ de BUP, por razones que desconocemos, aunque atribuímos al azar.

En cualquier caso, las explicaciones a la opción que consideramos más válida del apartado $\mathrm{A}$ (opción b) suelen ser bastante pobres, a veces de carácter tautológi$c o$. Unas veces relacionaban la profundidad del suelo con la longitud de las raíces y otras veces utilizan el criterio del paso de suelo a roca madre. En alguna ocasión se llegó a utilizar conocimientos académicos relevantes con el caso. Entre las explicaciones no aceptables a la opción válida $b$ encontramos razonamientos que vienen a confirmar una visión deformada de los suelos y otros aspectos geológicos.

Otras opciones, no válidas, del apartado A fueron explicadas igualmente con razonamientos que denotaban ideas muy confusas. Así para la opción de profundiđad pequeña (a), se aluđió a la acepción vulgar de suelo como superficie que se pisa. Las opciones de profundidades mayores fueron más corrientes que ninguna, demostrando una visión en general desproporcionadamente grande de la profundidad del suelo; fueron razonadas utilizando argumentos en los que se relaciona las aguas subterráneas con la profundidad del suelo. Otras veces se advierte la noción de que toda la Tierra está hecha de suelo, incluso en su interior, evidenciando confusiones entre estructura de la Tierra y la del suelo. Otras veces se utiliza el argumento comentado del tamaño de la raíz, aunque de forma inaceptable.

\section{Edad del suelo}

Al igual que en el caso anterior, este tópico fue probado con el item $n^{\circ} 9$, inspirado en el utilizado en el citado test de Happs (1982), aunque introduciendo igualmente algunas modificaciones importantes para nuestros propósitos (Anexo I). Las respuestas aceptables obtenidas en cada apartado pueden advertirse en la siguiente tabla (Gráf. 6):

\begin{tabular}{|c|c|c|c|c|c|c|c|c|c|c|c|c|}
\hline \multirow[t]{2}{*}{ It } & \multicolumn{2}{|c|}{$\begin{array}{c}7^{2} \mathrm{EGB} \\
12.13\end{array}$} & \multicolumn{2}{|c|}{$\begin{array}{c}8^{8} \mathrm{EGB} \\
13-14 \\
\end{array}$} & \multicolumn{2}{|c|}{$\begin{array}{l}18 \text { BUP } \\
14 \cdot 15\end{array}$} & \multicolumn{2}{|c|}{$\begin{array}{c}2^{2} \text { BUP } \\
15 \cdot 16\end{array}$} & \multicolumn{2}{|c|}{$\begin{array}{c}3^{9} \text { BUP } \\
16-17 \\
\end{array}$} & \multicolumn{2}{|c|}{ General } \\
\hline & A & B & A & B & A & B & A & B & $\mathbf{A}$ & B & $\mathbf{A}$ & B \\
\hline 9 & 15,0 & 1,3 & 7,8 & 6,5 & 17,6 & 3.9 & 26,0 & 6,0 & 27,3 & 9.0 & 17,3 & 5,1 \\
\hline
\end{tabular}

Entre las opciones, no se incluyó un intervalo superior a quince mil años por no introducir el concepto de «paleosuelo", normalmente no presente en los currículos del segmento estudiado y en todo caso lejano al concepto de suelo vivo o actual, situando como válida una opción más cercana al concepto de suelo que normalmente se maneja en estos niveles educativos.

Los resultados de la investigación confirman los hallazgos del mencionado autor sobre el hecho de que los alumnos de todas Ias edades tienen una idea muy confusa y a menudo errónea de la edad de los suelos, en gran parte ligada a un concepto general de suelo muy defectuoso, tal como se ha ido mostrando a partir de los resultados en otros tópicos de este concepto. Por otra parte, creemos que la cronología de la edafogénesis ha sido sistemáticamente obviada en los currículos escolares, situación ésta que ha podido favorecer la escasa noción detectada sobre este aspecto del concepto científico de suelo.

En efecto, Jos resultados generales obtenidos para este ítem muestran que sólo una ínfima cantidad (el 17,3\%) tiene una idea aproximada de la edad que puedan tener los suelos y, de ellos, una cantidad aún menor (un $5,1 \%$ ) da razones aceptables sobre la elección de esta opción, lo que puede significar que parte de esta proporción eligió al azar esta opción, es decir que la realidad es mucho menor. En cuanto a la evolución en la etapa (Gráf. 6), muestra una ligera tendencia a aumentar el nivel de respuestas aceptables a lo largo de aquélla, tanto en el apartado A como en el B, posiblemente por un mayor desarrollo de la noción de tiempo histórico/geológico asociado a la madurez mental del alumno. En cualquier caso, se confirma la dificultad piagetiana en torno a la noción de «tiempo», para el caso específico de «tiempo geológico», constatada anteriormente (Pedrinaci 1987, Yus y Rebollo 1987, etc.).

Entre las contestaciones que hemos considerado como aceptables (apartado B) para la opción válida del apartado A, en general muy pobres y cercanas a la tautología, 
Grafico 7

TEST DEL SUELO

Item núm. 3

\% Respuestas aceptables

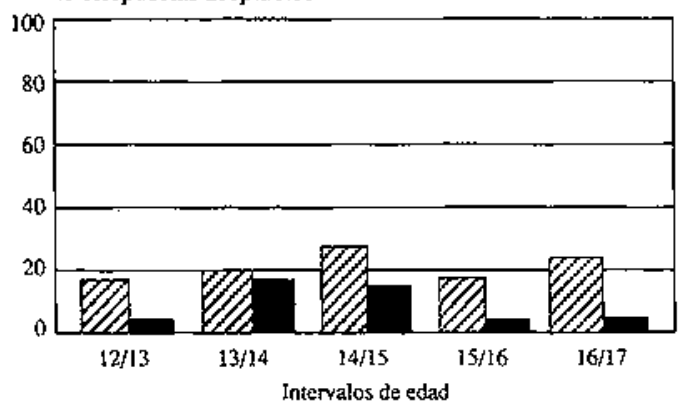

Q Aparado A Apartado B

Gráfico 9

TEST DEL SUELO

İten nứm. 12

\% Respuestas aceptables

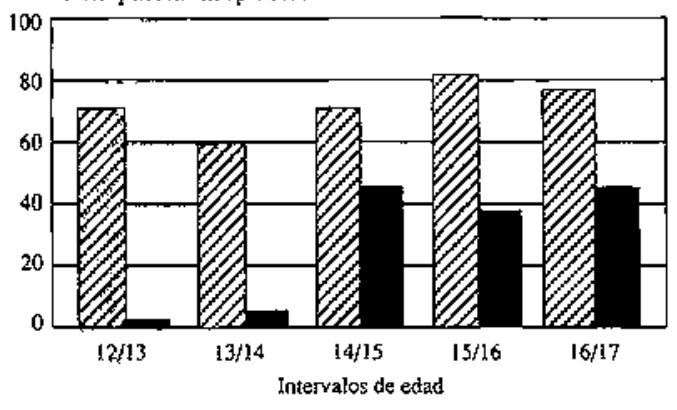

DZApartado A Apartado B

Gráfico 1I

TEST DEL SUELO

ftem núm. 7

\% Respuestas aceptables

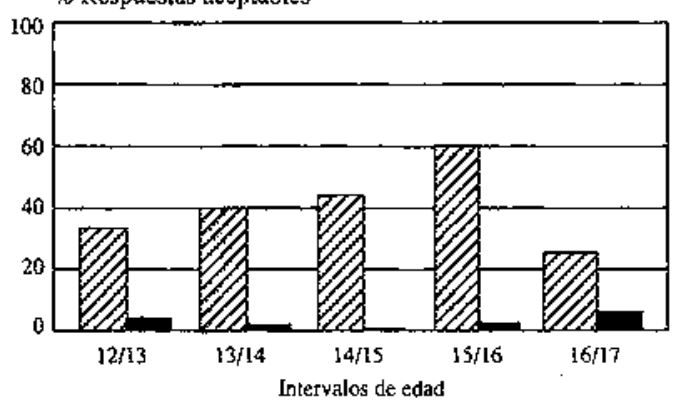

Grafico 8

TEST DEL SUELO

Item núm. 2

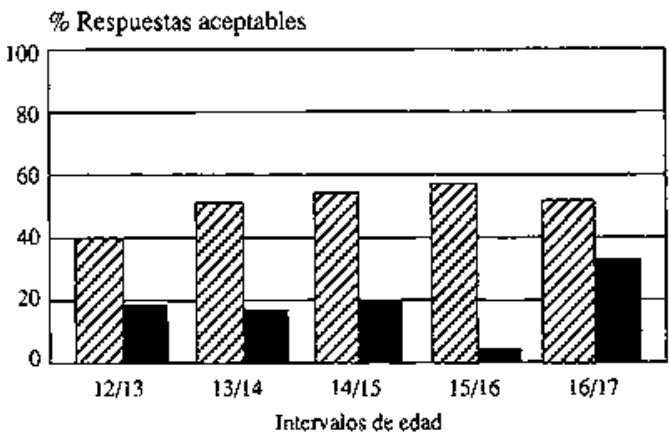

ZZ Apartado A Apartado B

Gráfico 10

TEST DEL SUELO

Ítem núm. $S$

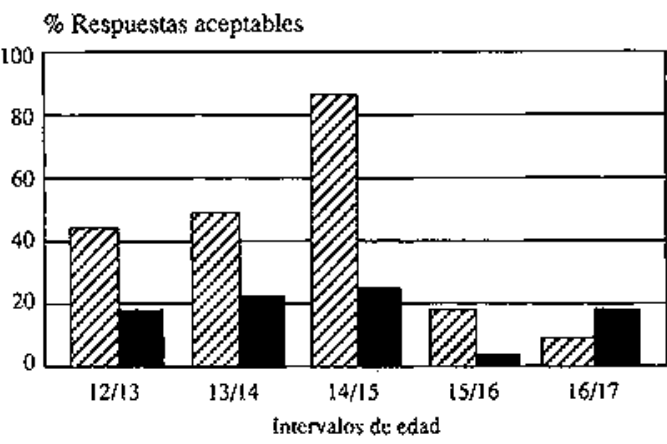

ZD Apartado A Apartado B

Gráfico 12

TEST DEL SUELO

İtem núm. 8

$\%$ Respuestas aceptables

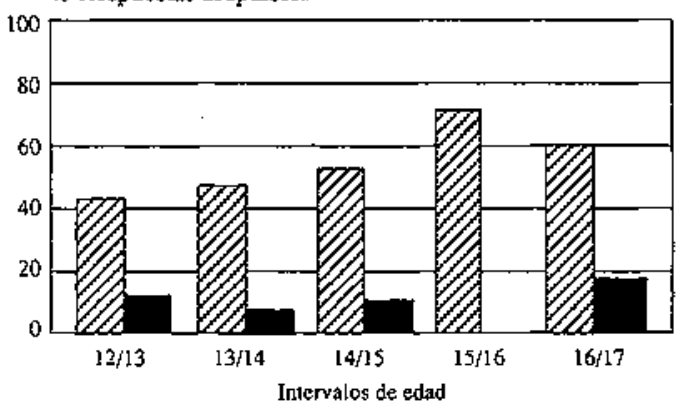

CA Apartado A Aparado B

ZD Apartado A

Apartado B

Gráfico 13

TEST DEL SUFLO

ftem núm. 11

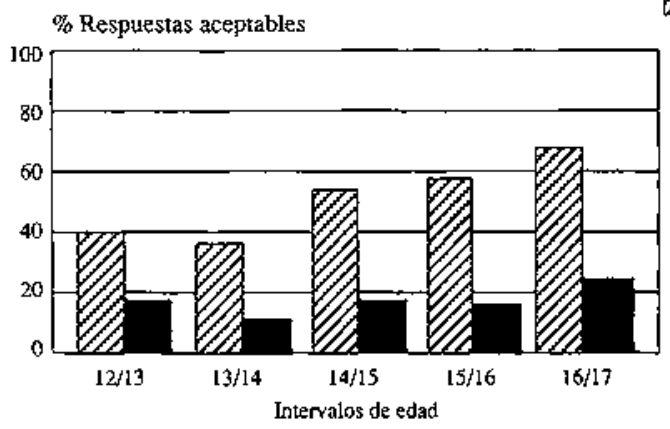

ED Apartado A

Apartarto B 
destacamos aquéllas que hacían referencia a la diferente cronología de acontecimientos entre formación de roca y suelo, o bien al tiempo que se estima en que se producen los fenómenos geológicos que dan lugar al suelo. Otras explicaciones a la opción válida no fueron tan aceptables; entre éstas figuran las que, una vez más, hacen referencia a una concepción de suelo relativa a una superficie que pisamos, o las que se refieren al aspecto físico que tendría, o a la lentitud de supuestos procesos edafogenéticos y que en ocasiones acuden a cronologías bíblicas.

Las opciones no válidas del apartado A fueron explicadas de forma variada. Así, un grupo importante loconstitiryó la opción $d$, que se refería a la edad de la Tierra, cuestión ésta que conecta con la conocida visión estaticista y creacionista de los procesos geológicos (Pedrinaci 1987, Yus y Rebollo 1987), en ocasiones mostrando como prueba la sincronía de la creación de todos los componentes del suelo, y en otras mostrando, una vez más, la aludida acepción vulgar de suelo como superficie para pisar.

\section{B) ASPECTOS PROCESUALES DEL CONCEPTO DE SUELO}

Otro grupo importante de aspectos relacionados con el suelo, esta vez con carácter más dinámico, se refería a los procesos edafogenéticos, normalmente descuidados en gran parte del segmento educativo estudiado, y sobre los que obtuvimos los siguientes resultados:

\section{Origen del suelo}

Se trató de hacer un sondeo a través del ítem $n^{0} 3$ (Anexo I). Los resultados pueden apreciarse en la siguiente tabla (Gráf. 7):

\begin{tabular}{|c|c|c|c|c|c|c|c|c|c|c|c|c|}
\hline & \multicolumn{2}{|c|}{$\begin{array}{c}7^{8} \text { EGB } \\
12-13\end{array}$} & \multicolumn{2}{|c|}{$\begin{array}{c}8^{2} \text { EGB } \\
13 \cdot 14\end{array}$} & \multicolumn{2}{|c|}{$\begin{array}{c}1^{2} \text { BUP } \\
14.15 \\
\end{array}$} & \multicolumn{2}{|c|}{$\begin{array}{l}2^{8} \text { BUP } \\
15.16 \\
\end{array}$} & \multicolumn{2}{|c|}{$\begin{array}{c}3^{2} \text { BUP } \\
16 * 17\end{array}$} & \multicolumn{2}{|c|}{ Genera } \\
\hline & A & & & & & & & & & & & No \\
\hline & & & & & & & & & & & & \\
\hline
\end{tabular}

en la que hay dos partes muy relacionadas: $a$ ) afecta a las condiciones de formación del suelo, y $b$ ) afecta al proceso de formación del suelo. Aunque en el dibujo se representa una situación anómala (hay árboles y sin embargo se pide que se suponga que aún no se ha formado suelo), se pretendía detectar la idea, advertida en el estudio preliminar, de que los alumnos tienden a considerar el origen del suelo como un proceso alóctono, cercano o equivalente a la sedimentación. En efecto fue así y la riqueza o diversidad de explicaciones no ocultaban un hecho comúnmente admitido: la idea de que el suelo se forma por un proceso de sedimentación de materiales acarreados por algún agente geológico. En términos generales la proporción de respuestas correctas al apartado $\mathrm{A}$ fue muy pequeño $(19,3 \%)$, pero cuando se hacía esta elección, la explicación (apartado B) solía ser correcta $(14,6 \%)$.
Respecto a la evolución de este concepto en la etapa considerada (Gráf. 7), se advierte un débil aumento progresivo en el poder explicativo conforme se avanza en la edad, aunque no de forma muy significativa, alcanzándose un máximo de respuestas acertadas en $1^{\circ}$ de BUP $(27,5 \%)$, si bien las explicaciones estaban muy por debajo de esta cifra (13,7\%). Llama la atención el hecho de que el nivel de explicaciones (apartado B) sea muy similar en los primeros años y en los últimos, mostrándose la escasa incidencia de los aprendizajes a lo largo de la etapa.

Entre las respuestas al apartado $b$, sobre el origen del suelo, que hemos considerado como «aceptables», aparecen contestaciones que estaban en sintonía con una concepción inercial del suelo, como producto de un proceso geológico, más bien mecánico. En otros casos se hace referencia al tiempo geológico. Más adelante ya se apunta el papel de los seres vivos, posiblemente inducidos por la inclusión de árboles en el dibujo de la pregunta.

Sin embargo, la mayoría de las respuestas noeran aceptables científicamente, mostraban la comentada visión de un origen alóctono del suelo, producto de la sedimentación de materiales procedentes de otro lugar, merced a diversos agentes geológicos, llegándose a apuntar un origen tec. tónico, que mostraba una concepción catastrofista de los procesos geológicos, ya detectada en otros estudios (Pedrinaci 1987, Yus y Rebollo 1987) o incluso del espacio sideral. Más adelante se incluye algún ser vivo y finalmente se asienta la idea del papel del río.

Esta visión del suelo como un producto de acarreo mueve a los alumnos a elegir la opción $b$, que representa la vega de un río (B), pues es allí donde se dan las mejores circunstancias para que se depositen materiales. En otros casos, esta opción se debe a la relación que se establece entre las plantas y el agua, obviándose el hecho de que lo que se habla es del suelo y no de las plantas, lo que significa que los alumnos incluyen entre los atributos de «buen suelo», el que disponga de agua, siempre en función de su papel potencial para albergar vida vegetal. También se destaca la importancia de la «tierra»o los «sedimentos» frente a las rocas.

Una proporción nada despreciable consideraba más probable la formación del suelo en $\mathrm{A}$, lugar señalado con la presencia de roca (pizarras). En este caso, los alumnos utilizaban distintos argumentos para fundamentar esta opción. En algunas ocasiones señalan el carácter llano del terreno, si bien esto también se da en B, donde en cambio no se le reconoce esta capacidad por circunstancias diversas. Para explicar el origen del suelo en A se acude frecuentemente a los procesos mecánicos, tendientes a la demolición de la roca. En otras ocasiones vuelve a aflorar la acepción vulgar del término suelo como «superficie para pisar», justificando las mejores condiciones de A por su mejor estado para el «pisoteo» o Ia edificabilidad.

Incluso muchas de las explicaciones a la elección correc. ta del apartado A (opción $c$ ) no eran aceptables científicamente, mostrando en muchos casos la persistencia de 
concepciones más ligadas a las otras opciones, como la explicación de la formación de suelos por acarreo o sedimentación, o bien aferrándose a la existencia de vegetación y desoyendo la convención de que el suelo aún no se había formado.

\section{Factores edafogenéticos}

Este aspecto fue abordado con dos items: el $n^{0} 2$ y el $n^{\circ}$ 12, formulados de manera complementaria (Anexo I) y cuyos resultados pueden mostrarse en la siguiente tabla (Gráf. 8 y 9):

\begin{tabular}{|c|c|c|c|c|c|c|c|c|c|c|c|c|}
\hline \multirow[t]{2}{*}{ It } & \multicolumn{2}{|c|}{$\begin{array}{c}7^{9} \mathrm{EGB} \\
12 \cdot 13\end{array}$} & \multicolumn{2}{|c|}{$\begin{array}{c}8^{2} \text { EGB } \\
13-14\end{array}$} & \multicolumn{2}{|c|}{$\begin{array}{c}1^{\circ} \text { BUP } \\
14-15\end{array}$} & \multicolumn{2}{|c|}{$\begin{array}{c}2^{2} \mathrm{BUP} \\
15-16 \\
\end{array}$} & \multicolumn{2}{|c|}{$\begin{array}{c}3^{2} \text { BUP } \\
16.17\end{array}$} & \multicolumn{2}{|c|}{ General } \\
\hline & $\mathbf{A}$ & B & $\mathbf{A}$ & B & A & B & A & B & A & B & $\mathbf{A}$ & B \\
\hline 2 & 40,4 & 16,4 & 50,6 & 15,1 & $\$ 4,9$ & 19,6 & 56,0 & 10,0 & 50,0 & 34,0 & 49,6 & 13,0 \\
\hline 12 & 71,2 & 2,7 & 59,2 & 7,8 & 72,5 & 47,6 & 82,0 & 38,0 & 75,0 & 50,0 & 70.7 & 21,7 \\
\hline
\end{tabular}

En efecto, mientras en el $n^{2} 2$ se trataba de ver qué factores eran considerados como los más importantes en la formación del suelo, en la n ${ }^{0} 12$ ya se partía del hecho (constatado en el estudio preliminar) de que es el clima el factormás ampliamente admitido por todos los alumnos de todas las eđades, y por ello se sondea qué tipo de clima es el que considera que es más beneficioso para la formación del suelo. En el ítem $n^{2} 2$ exigíamos a los alumnos a jerarquizar los factores edafogenéticos, ya que tenían que optar por tan sólo dos factores que consideraran los más influyentes en la formación deI suelo.

El resultado de la encuesta nos muestra que, en efecto, en el ítem $\mathrm{n}^{\circ} 2$, aproximadamente la mitad de los alumnos $(49,6 \%)$ eligió la respuesta que consideramos más correcta del apartado A (opciones $a$ y $c$ ), aunque como ocurre en otros ítems, la proporción de explicaciones científicamente aceptables a esta opción (apartado B) fue mucho menor $(13,0 \%)$. Situados ya en el ítem $n^{2} 12$, una gran mayoría de los alumnos $(70,7 \%)$ eligió la respuesta correcta del apartado $\mathrm{A}$ (opción $d$ ), siendo también muy pobre y no aceptables científicamente las razones de su elección (apartado B), alcanzándose sólo el $21,7 \%$ de todos los encuestados.

La evolución de esta concepción a lo largo de la etapa es bastante débil en ambos ítems (Gráf. 8 y 9). Así, en el ítem $n^{\circ} 2$ se alcanza un máximo entre $1^{\circ}$ y $2^{\circ}$ de BUP, siendo muy similares los porcentajes en los primeros y últimos cursos (en torno al $50 \%$ ), cosa que no ocurre con el apartado B, ya que las explicaciones eran más ricas y aceptables en el último curso $(34,0 \%)$ frente a la baja proporción obtenida en $8^{\circ}$ de EGB $(15,1 \%)$. Respecto al ítem no 12 la situación cambia, pues se advierte que, pese a que Ia evolución đe respuestas aceptables al apartado A es muy đébil, obteniéndose un máximo en $2^{\circ}$ de BUP $(82 \%)$, en cambio sí hay una clara evolución en las explicaciones (apartado B), obteniéndose diferencias importantes entre los alumnos de EGB (no superando el $10 \%$ ) y los de BUP (que alcanzan el $50 \%$ en $3^{\circ}$ de BUP), lo que explicamos en parte por el hecho de disponer estos alumnos de mayores conocimientos físico-químicos, básicos para explicar la acción de la atmósfera, tras el paso por esta disciplina en $2^{\circ}$ de BUP, si bien sus explicaciones eran frecuentemente confusas.

Las características del ítem $n^{\circ} 2$ hacían que, pese a que alguna elección del apartado A no era la que nosotros habíamos considerado como más aceptable (opciones $a$ y $c$ ), en cambio sí estaban bien fundamentadas en el apartado $B$. En primer lugar, entre las explicaciones que hemos catalogado como aceptables (apartado B) respecto La opción «a/c» en el ítem $n^{\circ} 2$, figura un grupo que fundamenta la elección del clima en tanto que favorece el crecimiento de las plantas, pero sin hacer referencia a su papel en los procesos químicos del suelo; y respecto a la opción $c$ (inclinación del terreno) se razonaba por su relación con la retención del agua e incluso las sales minerales.

Otras opciones del apartado $\mathrm{A}$, menos importantes para la formación de suelo, se catalogaron como «no aceptables», no obstante fueron explicadas aceptabiemente, aunque siempre en una tónica de factores que favorecen el desarrollo de las plantas más que el del suelo propiamente dicho. Aś́, para muchos alumnos el estiércol es importante porque abona/enriquece a la tierra y esto es bueno para las plantas. En pocas ocasiones eligen el tipo de roca (opción d) que, aunque aceptable científicamente (de importancia menor respecto a la $a$ y $c$ ), en cualquier caso no era apoyada por una explicación aceptable, frecuentemente relativa a la mayor o menor adecuación a la edificabilidad, utilizando la acepción vulgar del término suelo. Otras veces, eligen la existencia de vegetación, pero por razones no aceptables, como la de «dar sombra» al suelo.

Entre las opciones no aceptables del ítem $n^{2} 2$ destaca la $b$ (la agricultura) que incluímos por haber sido detectada esta idea en el estudio preliminar. En efecto, una proporción importante de alumnos, especialmente los que son de ambientes rurales, están convencidos del papel beneficioso de la agricultura en la formación de suelos y esto lo razonan por los cuidados intensivos del suelo por parte del hombre, decreciendo su importancia en cursos superiores, que coinciden con ser los más urbanos, o bien señalan vagamente su papel negativo. En estrecha relación con la opción $b$ está la $g$ (el estiércol), cuyo papel es mal conocido por los mismos alumnos que optaron por este factor, destacando explicaciones vagas e inaceptables, frecuentemente relacionadas con la concepción heterotrófica de la nutrición vegetal. Otras opciones no aceptables se razonaban a partir de la concepción de suelo como superficie para pisar o edificar.

Situados en el ́́tem $n^{\circ} 12$, en el que se analiza el tipo de clima más favorable para la formación del suelo, destaca la escasa argumentación (apartado B) de los primeros cursos a la elección correcta de la opción $d$ (clima lluvioso y cálido). Así, en alguna ocasión se han detectado explicaciones vagas, cercanas a la tautología. En $1^{\circ}$ de BUP destaca el hecho de que se utilizan conocimientos académicos, decreciendo la riqueza de explicaciones en los últimos cursos. 
Sin embargo, pocas explicaciones a la opción $d$ (clima lluvioso y cálido) del ítem $n^{2} \backslash 2$ fueron aceptables, ya que a menudo éstas eran confusas, siempre relacionándose con la nutrición vegetal, entendida de forma inapropiada, más cercana a la fisiología animal (nutrición heterótrofa) que a la vegetal (nutrición autótrofa) y rara vez en relación con el desarrollo del suelo propiamente dicho. Dentro de las explicaciones relacionadas con la nutrición vegetal, los alumnos solían explicar mejor el papel de ia lluvia (como fuente de agua, de riego) que el papel del calor, que a menudo quedaba en tautologías o explicaciones confusas. Así unas respuestas mostraban un papel físico de la lluvia sobre las plantas, o bien sobre el propio suelo, o en relación a la agricultura, o bien para determinados órganos de la planta. Otros relacionan el calor con la luz, a veces relacionando calor como fuente energética, o bien diferencian tipo de plantas con tipo de clima, haciendo gala de conocimientos adquiridos en el entorno rural, o bien la exigencia de uno u otro según las estaciones. Finalmente, otras explicaciones eran coherentes con la comentada acepción vulgar del término suelo, como superficie para pisar.

Entre las opciones no aceptables del apartado A del ítem $\mathrm{n}^{\mathrm{Q}} 12$, destaca Ia opción $a$, que hace referencia a un «clima seco y cálido». Entre las explicaciones que se utilizaron para defender esta opción figuran unas que hacían referencia al papel erosivo del agua de la Iluvia, de forma contraria a los planteamientos aceptados sobre el papel de los climas áridos en la desertización y pérdida de suelos. Otras veces se hacía referencia al volumen de material, o bien a las condiciones de formación del mismo, a veces señalando, una vez más, la acepción vulgar del término suelo, como superficie para pisar.

\section{Edafogénesis}

Éste fue el aspecto más indagado y para ello se utilizaron tres f́tems: $5^{\circ}, 7^{\circ}$ y $8^{\circ}$ (Anexo I) cuyos resultados resumimos en la siguiente tabla (Gráf. 10, 11 y 12):

\begin{tabular}{|c|c|c|c|c|c|c|c|c|c|c|c|c|}
\hline & \multicolumn{2}{|c|}{$\begin{array}{c}7^{2} \mathrm{EGB} \\
12-13\end{array}$} & \multicolumn{2}{|c|}{$\begin{array}{c}8^{2} \text { EGB } \\
13-14\end{array}$} & \multicolumn{2}{|c|}{$\begin{array}{c}1^{8} \text { BUP } \\
14-15\end{array}$} & \multicolumn{2}{|c|}{$\begin{array}{c}2^{2} \text { BUP } \\
15-16 \\
\end{array}$} & \multicolumn{2}{|c|}{$\begin{array}{c}3^{2} \text { BUP } \\
16-17 \\
\end{array}$} & \multicolumn{2}{|c|}{ Gener } \\
\hline & $\mathbf{A}$ & & A & & & & & & & & & \\
\hline & & & & & & & & & & & & \\
\hline & & & & & & & & & & & & \\
\hline & 45,2 & $\mid 12,3$ & 47 & & & $\mid 11,7$ & 7 & 0 & 61,3 & 15,9 & & \\
\hline
\end{tabular}

Todos ellos iban dirigidos a detectar las concepciones sobre los procesos de formación y evolución del suelo, si bien también se pudo detectar indicios de estas concepciones a partir de las explicaciones al ítem $3^{\circ}$, como mostraremos a continuación. Todos estos ítems hacen referencia al «sentido» de la formación del suelo, con objeto de detectar la visión de los alumnos de la procedencia de los procesos edafogenéticos, bien entendido que, tal como detectamos en el estudio preliminar, había una tendencia a utilizar el esquema de sedimentación en la formación de suelo, como se probó en el ítem $3^{\circ}$.
El ítem n 5 fue contestado aceptablemente por cerca de la mitad de los encuestados $(48,2 \%)$, si bien las explicaciones fueron muy pobres, erróneas o ausentes $(19,0 \%)$. No obstante, líma la atención la importante cantidad de alumnos que consideran que el suelo se forma por acumulación de tierra sobre una roca inalterable. Cifras similares, que muestran la misma concepción, se obtuvieron en los restantes ítems. Así, en el nº 7 ; el 40,4\% de los encuestados eligió la respuesta adecuada, si bien prácticamente ninguno (4\%) halló una explicación aceptable. Finalmente, en el ítem $n^{9} 8$ se encontró una cifra algo superior $(54,0 \%)$ que eligió la respuesta correcta, aunque la proporción de explicaciones aceptables fue considerablemente menor $(9,5 \%)$. En todos los casos se obtuvo una insuficiencia real en el bagaje de conocimientos sobre los procesos edafogenéticos, mostrando que esta temática era prácticamente desconocida o mal comprendida por la mayoría de los encuestados.

Respecto a la evolución de estas concepciones en la etapa, una vez más advertimos una homogeneidad de concepciones, salvando un nivel destacado en $1^{\circ}$ de BUP (14-15), probablemente por estar influidos de la instrucción reciente sobre este tópico, y en $2^{2}$ de BUP para los casos en que son precisos los conocimientos físico-químicos (Gráf. 10,11 y 12). En el ítem no 5 , en $1^{\circ}$ de BUP se muestra un porcentaje muy superior de respuestas aceptables en el apartado $A(86,2 \%)$, si bien el nivel de explicaciones (apartado B) fue muy escaso (18,0\%); llama la atención la menor proporción de respuestas aceptables en los niveles superiores, en comparación con los inferiores, contrastando el $51,3 \%$ alcanzado por $8^{2}$ de EGB con el $10,9 \%$ alcanzado por $3^{\circ}$ de BUP. En cuanto al ítem $n^{2} 7$, se advierte igualmente una evolución progresiva en la etapa, mostrando un máximo entre $1^{\circ}$ y $2^{\circ}$ de BUP $(60,0 \%)$, bajando bruscamente de nuevo en $3^{\circ}$ de BUP $(25,0 \%)$, que se sitúa muy por debajo del nivel alcanzado por los primeros cursos (entre el 30-40\%). No obstante, el nivel de explicaciones (apartado $B$ ) fue muy pobre en general, mostrándose un máximo en $3^{\circ}$ de $B U P(6,8 \%)$, probablemente por el manejo de conocimientos de tipo físico-químico, claves para la comprensión del fenómeno que se enjuiciaba. Finalmente, en cuanto al f́tem $n^{0} 8$, la situación es similar a la del $\mathrm{n}^{\circ} 7$, aunque con un porcentaje general mayor de respuestas aceptables en cada nivel, mostrándose un máximo entre los cursos $2^{\circ}$ y $3^{\text {o }}$ de BUP $(72,0 \%$ y $61,3 \%$, respectivamente). Sin embargo, llama la atención la ausencia de explicación en $2^{\circ}$ de BUP, frente a una importante cifra alcanzada en $3^{\circ}$ (15,9\%), aunque siempre en la acostumbrada tónica de desproporcionalidad respecto al nivel alcanzado en el apartado $\mathrm{A}$.

En cuanto a las explicaciones aceptables a las opciones del ítem $n^{\circ} 5$ (apartado B), figuran las que inicialmente en la etapa reveian una concepción exclusivamente mecánica o física de la edafogénesis. Más adelante, en $1^{\circ}$ de BUP se apunta la intervención de los seres vivos y una concepción más completa de la edafogénesis, bajando de nuevo en argumentación en $2^{\circ}$ y $3^{\circ}$ de BUP. Pero no todas las explicaciones a la opción válida $b$ fueron aceptables, a menudo con intervención humana o agentes geológicos internos o tectónicos. 
Sin embargo, fue mayor el porcentaje de explicaciones no aceptables, naturalmente relacionadas con la opción errónea $a$ (el suelo se forma por acumulación de materia). Entre las explicaciones usadas aparecen las que representan una confirmación de esta concepción de un origen exógeno del suelo, unido a una concepción estaticista de las rocas, en ocasiones con un origen extraterrestre, acudiendo a menudo a la inclusión de restos orgánicos, como fuente externa, lo que es aceptable, aunque no como fundamento general para la formación de suelo, o incluso explicaciones muy singulares, de carácter tectónico.

En relación con las explicaciones del apartado $B$ del ítem $n^{\circ} 7$, es preciso señalar la práctica ausencia de alguna explicación suficientemente aceptable, que indique que el proceso de producción de caliche es por ascensión capilar de aguas carbonatadas y precipitación por acción del calor. Con ello pretendíamos comprobar que el alumno sólo considera un sentido descendente de los procesos físico-químicos del suelo. Entre las muy escasas explicaciones que se acercan más a lo aceptable, destacamos las que conjugan el calor con el movimiento vertical del agua, si bien omitiendo el proceso de disolución del carbonato, cosa que se admite en otras explicaciones que por el contrario no indican el mecanismo de disolución y de ascensión (12-13). Más adelante no mejora la explicación, faltan el proceso de disolución y el mecanismo de ascensión (14-15), o bien se da la impresión de entenderse como un proceso exclusivamente físico (en algún caso aislado se llega a apuntar el mecanismo físico).

Entre las explicaciones no aceptables a la opción $a$, figuran las que señalan un proceso mecánico o clásico de fơrmación del caliche, acudiéndose a veces a explicaciones muy forzadas, con componentes tectónicos, o acudiendo a la flotabilidad (?). En otros casos, se considera que son simples clastos que no se han alterado. Finalmente, entre las explicaciones a las restantes opciones, no aceptables, del apartado A, figuran representaciones que atribuyen al agua de la Iluvia o de torrentes la presencia de cal, obligando a considerar que tales agentes lievan esta sustancia en disolución o suspensión, o bien adquieren un papel erosivo, o se atribuye al clima, o incluso a los seres vivos.

En cuanto a las explicaciones aceptables que se dieron a la opción válida del apartado $\mathrm{A}(\mathrm{c})$ del ítem $n^{\circ} 8$, destacamos aquéllas que incluyen tanto procesos edafogenéticos ascendentes (de abajo a arriba: la roca) como descendentes (de arriba a abajo: los agentes climáticos y bióticos), con objeto de decantar concepciones proclives a considerar sólo uno de estos sentidos.

Sin embargo, no todas las explicaciones a esta opción $c$ fueron aceptables, destacando unas que mostraban el papel del hombre, o una concepción de suelo de tipo sedimentario, o bien por las exigencias biológicas, incluso con explicaciones tectónicas o por la creencia de existencia de aguas subteráneas.

Entre las explicaciones a las opciones no aceptables deI apartado $\mathrm{A}$ del f́tem $\mathrm{n}^{\mathrm{e}} 8$, destacan un primer grupo que consideran sólo los procesos que provienen de la tierra (opción $b$ ). Otras consideran sólo los procesos que vienen de arriba (opción $a$ ).

\section{Intervención humana en el suelo}

Para probar este aspecto del suelo, hemos utilizado el ítem no 11 (Anexo I), cuyos resultados pueden apreciarse en la siguiente tabla (Gráf. 13):

\begin{tabular}{|c|c|c|c|c|c|c|c|c|c|c|c|c|}
\hline & \multicolumn{2}{|c|}{$\begin{array}{c}7^{\circ} \text { EGB } \\
12-13 \\
\end{array}$} & \multicolumn{2}{|c|}{$\begin{array}{c}8^{2} \text { EGB } \\
13 \cdot 14 \\
\end{array}$} & \multicolumn{2}{|c|}{$\begin{array}{c}\mathbf{1}^{\mathbf{B}} \mathbf{B U P} \\
14-15 \\
\end{array}$} & \multicolumn{2}{|c|}{$\begin{array}{c}2^{2} \text { BUP } \\
15-16 \\
\end{array}$} & \multicolumn{2}{|c|}{$\begin{array}{c}3^{2} \text { BUP } \\
16-17 \\
\end{array}$} & \multicolumn{2}{|c|}{ Genera } \\
\hline & A & & & & & & & & & & & \\
\hline & & & $|34,2|$ & & $\mid 50,9$ & 15,6 & $54,0 \mid$ & & & & & 15 \\
\hline
\end{tabular}

Esta cuestión se basaba en la idea, detectada en el estudio preliminar, de que los alumnos otorgan un papel importante a la intervención humana sobre el suelo (agricultura) en la conservación y evolución del mismo, contravíniendo la visión científicamente aceptable, según la cual en ocasiones la intervención agrícola, apropiada para fines de explotación, provoca alteraciones muy importantes, a veces irreversibles, en los procesos naturales de maduración del suelo, hasta el punto de llegar a agotarlo y desertizarlo.

Considerada la etapa globalmente, podemos afirmar que algo menos de la mitad de los alumnos $(47,2 \%)$ admite que el suelo se desarrolla mejor en el bosque (opción c), si bien el nivel de explicación aceptable a esta opción (apartado B) es, como siempre, muy bajo $(15,9 \%)$. No obstante, no se puede desdeñar el hecho de que aproximadamente la mitad de los alumnos encuestados de todas las edades considere que la agricultura es beneficiosa para la maduración del suelo. Si observamos la evolución a lo largo de la etapa (Gráf. 13), observaremos que en general se produce una progresión en el nivel de opciones aceptables, desde un mínimo alcanzado en $8^{\circ}$ de $\operatorname{EGB}(34,2 \%)$ hasta un máximoen $3^{\circ}$ de $\operatorname{BUP}(68,1 \%)$, mostrando una progresión paralela en el nivel de explicaciones del apartado B. Estas diferencias podían ser atribuidas al peso de la cultura agrícola en los primeros cursos, que coinciden con ser de centros de entornos rurales, aunque también podría influir el progresivo aumento de cultura general.

Entre las explicaciones aceptables a la opción que hemos considerado válida (opción c), destacan aquéllas que hacen referencia al papel de la vegetación en la formación de 1 componente orgánico o fertilizador, o bien a su poder de retención del suelo. Otras explicaciones a la opción válida $c$ no eran tan aceptables o eran incompletas, en ocasiones indicaban la potencialidad erosiva de esta zona o bien señalaban esta opción en función de su potencialidad como superficie para pisar, emergiendo de nuevo esta conocida concepción, o bien mostrando la concepción de suelo como producto de sedimentación.

Un grupo importante de opciones no aceptables se refirió al suelo agrícola (opción $b$ ), que fue explicado de la forma más variada e inaceptable; aludiendo a la importancia de la intervención humana, a una supuesta mayor 
fertilidad, a la supuesta existencia de más de tierra e, incluso, al hecho de estar más expuesto al sol, o se consideraba positivo que estuviera más sometido a la erosión. En algún caso se evidencia de nuevo la comentada concepción vulgar de «suelo».

Finalmente, un grupo pequeño estuvo formado por contestaciones que, sorprendentemente eligieron la opción $a$ (arena de playa), to cual fue explicado (apartado B) apoyándose en unas supuestas mejores condiciones para la acumulación de tierra o arena, lo que significa una concepción de edafogénesis por sedimentación, presente a lo largo de toda la etapa.

\section{CONCLUSIONES}

1. El instrumento de detección constituye una herramienta válida, en términos generales, para la detección de preconcepciones sobre el suelo en alumnos de este tramo educativo. Salvo algunos ítems que invitaban a la contestación tautológica, creemos que el conjunto es satisfactorio. Por otra parte, la consideración de dos apartados en cada ítem ha permitido la detección de aspectos cualitativos de las preconcepciones, revelándose una estrategia válida en estudios de amplio espectro, donde otras tếcnicas, como las entrevistas clínicas, son poco viables.

2. Se confirma gran parte de nuestras observaciones preliminares, advertidas desde la práctica docente, sobre eI hecho de que los alumnos manifiestan importantes dificultades en la comprensión del concepto científico de suelo. Lejos de ser este hecho superado por el tratamiento didáctico en la etapa secundaria, estas dificultades constituyen serios bloqueos no superables con procesos de enseñanza/aprendizaje basados en estrategias de transmisión.

3. En general podemos afirmar que los alumnos de $12 / 17$ años no tienen un concepto de suelo científicamente aceptable. Incluso muchos alumnos del comentado $12,2 \%$ de explicaciones aceptables mostraron una gran inseguridad y pobreza teminológica en sus explicaciones. Esta situación no manifiesta evolución progresiva a lo largo de la etapa, manteniéndose los niveles a lo largo de la misma. Tampoco parece que influya el hecho de que en determinados cursos se imparta el concepto de suelo con mayor profundidad.

4. Se constatan importantes dificultades derivadas de Ia polisemia del término "suelo» en nuestro idioma. Más allá de un mero problema semántico se trata de una dificultad que provoca que un porcentaje importante de alumnos tiendan a usar la acepción vulgar (como superficie que se pisa o edifica), aún conociendo la acepción científica, cuando se les plantea problemas relativos al concepto científico de suelo. Esta tendencia se aprecia de forma coherente en los diversos ftems y aparece en todo el segmento educativo, si bien con una tendencia leve a la disminución de su importancia conforme avanza la edad en la etapa.
5. Los alumnos suelen tener ideas vagas y confusas acerca de aspectos estructurales del suelo tales como: la edad (como sucede con otros procesos geológicos), profundidad (al incluir en el suelo el sustrato rocoso), composición (no suelen incluir el agua, aire y componentes biológicos) y estructura (confundida a menudo con la sedimentación).

6. Entre las representaciones del suelo en los alumnos, se han detectado dos grandes grupos conceptuales:

a) Un primer grupo to constituye el concepto de suelo como «superficie inerte o de soporte para pisar, edificar, o simplemente estar». Esta concepción debe atribuirse a la comentada acepción vuigar del término polisémico de suelo.

b) Otro grupo concibe el suelo como «producto del acarreo y sedimentación de productos de diversa índole, suelo, materia orgánica (generalmente cadáveres y restos), en virtud de diversos agentes.

c) Finalmente un grupo muy reducido liega a concebir el suelo como «el producto de la alteración/erosión de la roca». Aún en este caso, que podríamos catalogar como aceptable, los alumnos consideran que el suelo es un producto de un proceso mecánico o físico en el que no intervienen para nada los procesos químicos.

El grupo más importante lo constituye el $b$, siendo más importante el $a$ en los primeros cursos, pero no por ello ausente en los restantes. En cambio, el grupo $c$ era francamente minoritario, no superando el $12 \%$ del total de los encuestados. En todos los casos, esta representación es persistente a lo largo de la etapa, mostrando un alto grado de coherencia en las contestaciones a los diferentes ftems.

7. Si comparamos el nivel de explicaciones de los alumnos con la epistemología de este concepto a lo largo de la historia, podremos advertir que los alumnos se encuentran situados más o menos en los primeros estadios de la evolución de esta ciencia, bajo el paradigma agrológico, es decir: el «suelo como simple soporte de la vida vegetal». De algún modo también se incluiría un grupo que puede encuadrarse bajo el paradigma geodinámico: «el suelo como producto de la alteración de las rocas», aunque en su vertiente exclusivamente mecánica. En la epistemología de este concepto científico se advierte que, al igual que sucedió en la historia, los alumnos se encuentran bloqueados al no considerar la existencia de procesos químicos (geoquímicos y bioquímicos) propios del suelo y que actualmente podemos englobar, por su carácter interactivo, como procesos «ecoquímicos». Desde esta perspectiva, los alumnos encuestados se encuentran muy alejados del paradigma actual según ei cual el suelo se considera como un «microecosistema», al cual no pueden acceder mientras no amplíen su visión de los procesos edafológicos.

8. Un conclusión muy evidente es que los alumnos no manejan prácticamente ningún concepto químico en sus explicaciones. Para ellos no hay procesos químicos en el suelo, ni procedentes de la interacción atmósfera-roca, 
ni biosfera-roca. El único proceso que reconocen es puramente mecánico, ya sea por intervención de la atmósfera (agentes geológicos) como por los seres vivos (el hombre con la agricultura, Ias raíces de las plantas, etc.). El único aspecto que conceden como cercano a los procesos químicos del suelo es el papel de los abonos, del estiércol, de los desechos y cadáveres, si bien más en relación con la «alimentación» de los vegetales, que por la alteración química del sustrato mineral.

9. Finalmente, y como conclusión colateral de este estudio, se confirma la idea de que los alumnos mantienen ideas alternativas y otras representaciones acerca de los fenómenos geológicos. De este modo, hemos hallado una visión consistente en explicar tođos los fenómenos geológicos, incluso los de formación de suelos, acudiendo a teorías de tipo catastrofista o tectónico (volcanismo, terremotos, movimientos verticales, etc.) para explicar fenómenos que suceden con lentitud y merced a procesos externos. Tal como indicamos en otro trabajo (Yus Ramos et aI. 1987), los alumnos necesitan acudir a este tipo de explicaciones para poder ajustar la escala geocronológica a una escala más cercana a la de los seres humanos, dada la incapacidad, ya conocida en la psicología piagetiana, de manejar escalas diferentes de espacio y de tiempo: la rapidez de los fenómenos geotectónicos les permite explicar mejor algo que en realidad transcurre con un ritmo mucho más lento y duradero. Otra concepción que se confirma es la tendencia a otorgar al viento propiedades erosivas muy superiores a la de otros agentes geológicos que en la zona de estudio son más agresivos.

Entre las implicaciones que estos hallazgos tienen para el aula está la confirmación de que esta temática científica, como otras recogidas en la bibliografía especializa-

\section{REFERENCIAS BIBLIOGRÁFICAS}

HAPPS, J.C., 1982. Some aspects of student understanding of soil, The Australian Science Teachers Journal, 28(3), pp. 25-31.

PEDRINACI, E., 1987. Representaciones sobre los cambios geológicos, Investigación en la Escuela, 2, pp. 65-74.

YUSRAMOS, R. y GARCIA SÁNCHEZ, M., 1987. Resultados de una experiencia de aprendizaje constnuctivista de la Geología en el ciclo superior de la EGB, mediante el método $\mathrm{da}$, no se puede abordar con enfoques metodológicos superficiales, basados exclusivamente en la transmisión de conocimientos, sino que los alumnos han de utilizar formas de razonamiento superiores. Por otra parte, se ha de procurar que los alumnos asimilen unos mínimos conocimientos previos de tipo físico-químico para poder superar la visión agrológica del suelo. Esto supone una oportuna secuenciación de contenidos en el tramo 1216 , de tal suerte que no se debería impartir el concepto de suelo, más allá de aspectos perceptibles, sin antes haber introducido cierta visión de los procesos químicos, la naturaleza de la materia y el concepto de energía. Otros conceptos previos exigibles son de tipo geológico (conocimiento de los procesos geológicos extemos) y biológicos (nociones de microbiología, ciclo de la materia, nutrición vegetal, etc.). Con anterioridad a esta etapa no es posible alcanzar un cambio conceptual, pero los alumnos podrían ser instruidos acerca de la polisemia del término "suelo» y hacer ver, mediante imágenes reales, a qué se refiere la ciencia cuando utiliza este término y, todo lo más, constatar la diversidad de formas y desarrollos de suelos, aspectos cualitativos que no exigen grandes conocimientos científicos previos.

\section{AGRADECIMIENTOS}

Queremos mostrar nuestro agradecimiento a los profesores/as: Francisco Hernando del CP «A.S.Bellido» de Vélez-Málaga, Pedro Pages del CP «Colina del Sol» de Torrox, Antonio González del CP «R. Valle Inclán» de Arenas, Joaquín Goicoechea del IB «Sierra Bermeja» de Málaga, Mercedes Gervilla y Ángel Blanco del IB «Portada Alta» de Málaga, por su colaboración en la aplicación del instrumento de diagnóstico usado en esta investigación. de descubrimiento dirigido, Actas de las $V$ Jornadas de Estudio sobre Investigación en la Escuela, Sevilla, pp. 180.

YUS RAMOS, R. y REBOLLO BUENO, M., 1988. Elementos de un modelo didáctico de enfoque constructivista para la enseñanza de la Geología en el ciclo 12-16, Actas del V Simposio sobre Enseñanza de la Geología, Alcalá de Henares, p. 153.

YUS RAMOS, R. y REBOLLO BUENO, M.,199 $\$$. Curso de Ciencias Naturales: I. (Elzevir: Vélez-Málaga), 175 pp. (Guía del alumno), $124 \mathrm{pp}$. (Guía del profesor). 


\section{ANEXO I}

\section{TEST SOBRE LA CONCEPCIÓN DE SUELO}

1. A) ¿Qué entiendes por «strelo» cuando oyes esta palabra? (Señala una respuesta con una «x»).

a) La superficie que normalmente pisamos cuando andamos

b) La capa superficial de la Tierra donde se asientan los seres vivos

c) La tierra de labor o de cultivo

d) Otra cosa (especificar)

B) La razón de mì respuesta es porque:

2. A) ¿Cuáles de los siguientes factores son los que tienen mayor importancia en el desarrollo del suelo? (Señala con una «X» s6́lo 2 respuestas).
a) Clima
b) Agricultura
c) Inclinación del terreno
d) Tipo de roca
e) Tipo de plantas
g) Estiércol
h) Otro (especificar).

B) La razón de mi respuesta es porqque:

3. A) Supongamos que en la siguiente sección del terreno de un lugar del campo, aún no se ha formado «suelo»:

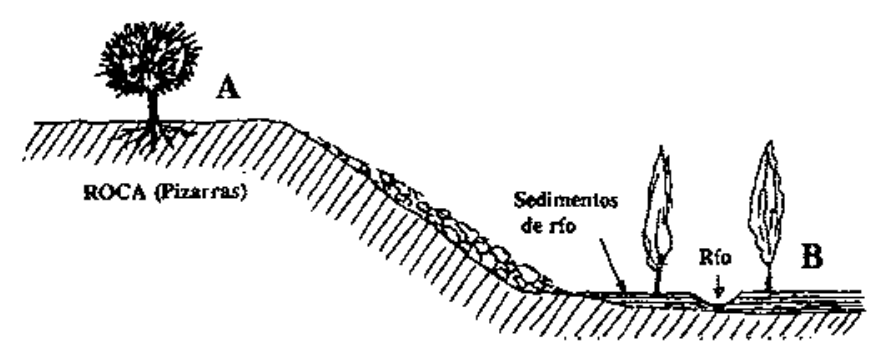

19 ¿Dónde crees que es más probable qque se desarrolle un «suelo» al cabo de cierto tiempo? (Señala una respuesta con una «X»).
a) En A
b) En $B$
c) En A y en B
d) En ninguno

B) La razón de mi respuesta es porq̣ue:

$\left.2^{\circ}\right)$ ¿De dónde crees que procede el suelo que se ha formado en $A$ o en $B$ o en ambos a la vez?

4. A) Si tuvieras que hacer una perforación en un bosque para averiguar la profundidad que tiene el suelo, $\Varangle$ a qué profundidad crees que habrá formado un suelo maduro? (Señala una sola respuesta con una «x»)
a) Entre $1 \mathrm{~cm}$ y $10 \mathrm{~cm}$
b) Entre I $\mathrm{m}$ y $10 \mathrm{~m}$
c) Entre $100 \mathrm{~m} \mathrm{y} 1 \mathrm{~km}$
d) Otra (especificar)

B) La razón de mi respuesta es porque:

5. A) ¿De dónde crees que procede la masa principal del «suelo»? (Señala con una «x» cuál đe las dos respuestas es la que más te convence).

a) De abajo a arriba (el espesor del suelo aumenta por acumulación de tierra que se deposita desde arriba). 


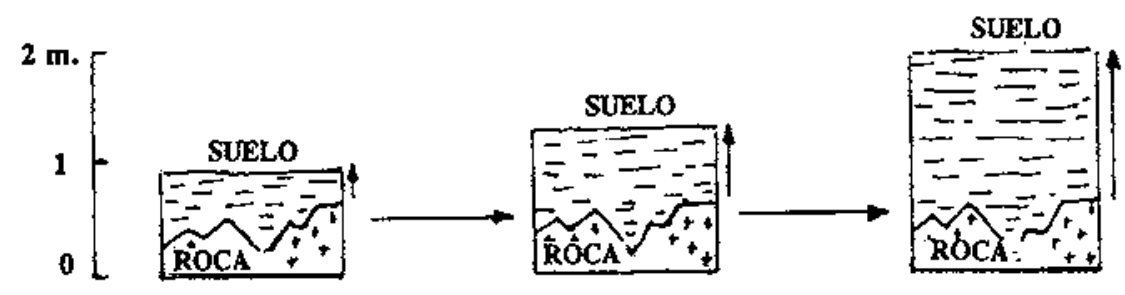

b) De arriba a abajo (el espesor del suelo aumenta por degradación, trituración o alteración de la roca que hay debajo, por lo que ésta va disminuyendo de espesor).

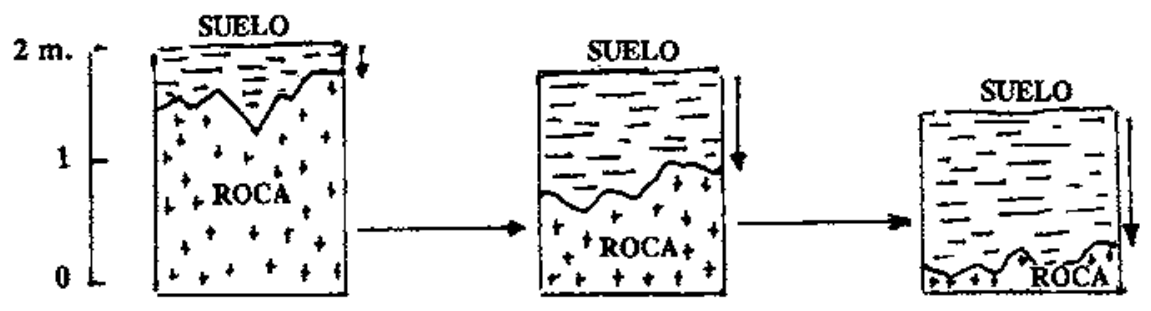

B) La razón de la respuesta que he escogido es porque:

6. A) ¿De qué está formado el suelo? (Señala con una «x» una sola respuesta).
a) Sólo de rocas trituradas y agua
b) De rocas trituradas, agua y plantas
c) De rocas trituradas, plantas y animales
d) De rocas trituradas, aire, agua, animales y plantas
e) De rocas trituradas, agua, plantas y animales
f) Otros (especificar).

B) La razón de mi respuesta es porque:

7. A) En los suelos de lugares áridos se forma una costra de cal (llamada «caliche») en la superfície. Sin embargo no hay cal (carbonatos) nada más que en la roca que hay debajo.

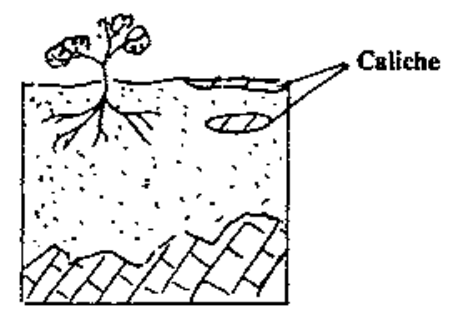

¿De dónde procede esta sustancia? (Cómo ha llegado hasta este lugar?) (Señala una sola respuesta con una «X»).
a) De la roca
b) De la Iluvia
c) De pequeños arroyos
d) Otra (especificar).

B) La razón de mi respuesta es porque: 
8. A) ¿De donde proceden los procesos o fenómenos que son responsables de la formación del suelo? (Señaia con una « $X » t u$ respuesta.)

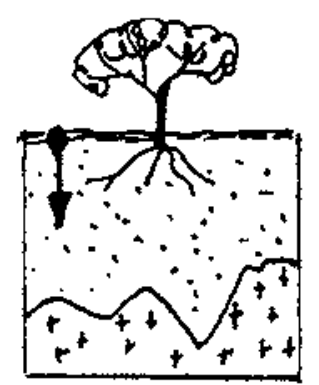

a) De arriba

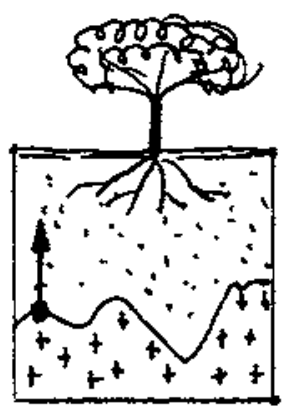

b) De abajo

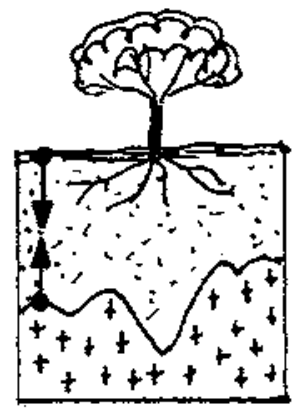

c) De ambas partes

B) La razón de la respuesta escogida es porque:

9. A) ¿Cuándo crees que se formaron los suelos que ves en la actualidad? (Señala con una «x» la edad que consideres más acertada):
a) Entre 1 y 100 años
b) Entre 100 y 15.000 años
c) Desde 1.000 .000 años en adelante
d) La misma edad que la Tierra

B) La razón de mi respuesta es porque:

10. A) En todos los suelos se encuentran unas capas a «horizontes» superpuestos.

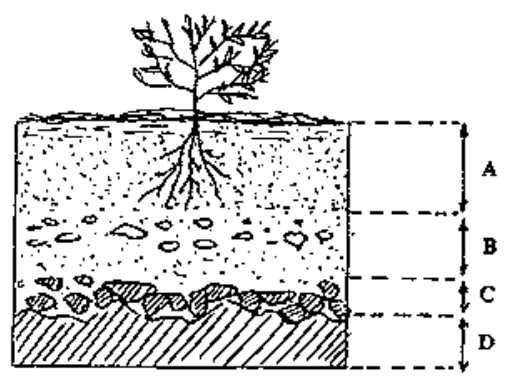

Señala con una « $x »$ el horizonte más reciente (el último que se ha formado):
a) $\mathrm{El}$ «A»
b) $E$ « «B»
c) $\mathrm{El}$ «C»
d) $\mathrm{El}$ «D»

B) La razón de mi respuesta es porque:

11. A) En el siguiente esquema, en el que se representa un Iugar en el que hay arenas de playa, un campo de cultivo y un bosque,

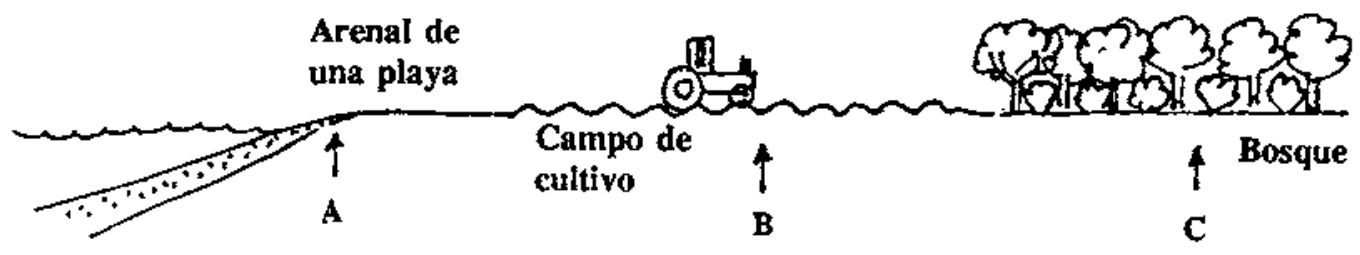


señala dónde crees que es más probable que se desarrolle un «suelo». (Señala una sola respuesta con una «x»).
a) En el arenal de la playa
b) En el campo de cultivo
c) En el bosque
d) Otro lugar (especificar):

B) La razón de mi respuesta es porque:

12. A) ¿De entre los siguientes climas, en qué lugar se formará un suelo de mayor desartollo? (Señala sólo una respuesta con una $\langle x »)$.
a) En un clima seco y cálido
b) En un clima lluvioso
c) En un clima frío y lluvioso
d) En un clima cálido y lluvioso
e) Otro clima (especificar):

B) La razón de mi respuesta es porque:

13. A) En un lago se encuentran las siguientes capas o estratos, depositados por sedimentación de los aportes de los ríos que desembocan en él.

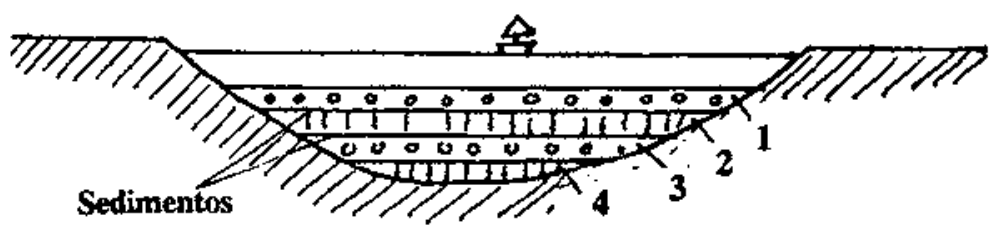

¿Cuál es Ia capa más antigua? (Señala una sola respuesta con una «X»),
a) La «I"
b) La «2»
c) $\mathrm{La} \ll 3 »$
d) $\mathbf{L a} \ll 4 »$
e) Otra respuesta (especificar)

B) La razón de mi respuesta es porque: 